\title{
A prematuridade e o desenvolvimento de linguagem
}

\author{
Comentado por: Zelita Caldeira Ferreira Guedes ${ }^{1}$
}

Marston L, Peacock JL, Calvert SA, Greenough A, Marlow N. Factors affecting vocabulary acquisition at age 2 in children born between 23 and 28 weeks' gestation. Dev Med Child Neurol. 2007;49(8):591-6.

Foster-Cohen S, Edgin JO, Champion PR, Woodward LJ. Early delayed language development in very preterm infants: evidence from the MacArthur- Bates CDI. J Child Lang. 2007;34(3):655-75.

Existe na literatura, um grande interesse sobre a influência do nascimento prematuro no desenvolvimento da linguagem. Vários autores têm demonstrado diferenças tanto na sua recepção como na sua expressão, manifestadas pelo tamanho do vocabulário, no atraso da aquisição, na complexidade da linguagem, no processo fonológico e na memória de curto prazo. Vários aspectos multifatoriais também têm sido estudados, na tentativa de se perceber sua real interferência.

Embora existam várias referências, nem sempre os estudos utilizam as mesmas variáveis ou o mesmo instrumento de análise para avaliar as crianças nascidas prematuras.

Foram analisados dois artigos escritos por equipes diversas, mas que se apropriaram do mesmo instrumento para avaliar suas diferentes populações. Um artigo é do Reino Unido* e outro é da Nova Zelândia** e foram editados na mesma época, por periódicos científicos diferentes. Entretanto, o objetivo foi o mesmo - verificar o quanto a prematuridade pode interferir no desenvolvimento de Linguagem - e o material utilizado em ambas as investigações foi o MacArthur-Bates Communicative Development Inventory (CDI-WS). Este teste de palavras e sentenças foi utilizado para averiguar o desenvolvimento de linguagem das crianças aos dois anos de idade. As crianças estudadas nasceram com idades gestacionais variando de menos do que 28 semanas até 38-41 semanas, quando são consideradas a termo.

A equipe de pesquisadores da Nova Zelândia salienta o fato de que diferentes datas de nascimento podem ocasionar variações no desenvolvimento de linguagem. Para eles, um dos principais objetivos deste estudo foi examinar a relação entre a produção de linguagem de crianças nascidas extremamente prematuras, prematuras e a termo.

Foram avaliadas 90 crianças prematuras e 105 a termo quanto ao tamanho de vocabulário e complexidade morfológica e sintática por meio do CDI-WS, que consiste num questionário realizado com os pais.

Outro objetivo deste grupo foi verificar as associações significantes entre a idade gestacional ao nascimento e a produção de linguagem e o quanto essas podem ser explicadas pelas características de potencial dos familiares e da criança

(1) Doutora, Professora Associada da Universidade Federal de São Paulo UNIFESP - São Paulo (SP), Brasil.

Endereço para correspondência: Zelita Caldeira Ferreira Guedes. R. Bandeira Paulista, 147/14, Itaim-Bibi, São Paulo - SP, CEP 04532-010. E-mail: zelitaferreira@uol.com.br ou realmente correlacionadas com a idade gestacional e desenvolvimento de linguagem.

Dois grupos foram formados, um de 90 crianças com idade média de 28 semanas e 1050 gramas de peso ao nascimento, que foi subdividido em extremamente prematuros (23-28 semanas) e prematuros (28-33 semanas) e outro de 105 crianças nascidas entre 38 e 41 semanas.

Duas semanas antes de completarem dois anos (idade corrigida para os prematuros) todos foram avaliados pela escala Bayley (1993) e pelo CDI-WS. Dados referentes às condições sociais foram obtidos com os pais durante as entrevistas realizadas.

A seção de palavras foi investigada por meio do reconhecimento de vocabulário dividido em 22 categorias semânticas, 11 de substantivos e as demais contendo outras categorias gramaticais. A seção de sentenças e gramática continha 125 itens organizados de acordo com o desenvolvimento sintático e morfológico, como formas regulares e irregulares e uso de sentenças com níveis diferentes de complexidade.

$\mathrm{O}$ cálculo de medidas referente às respostas obedeceu ao manual de instruções.

Aos pais foi questionado também como seus filhos podiam expressar noções de espaço e tempo.

Os dados sócio-econômicos e culturais de cada família também foram analisados.

Cinco análises estatísticas foram realizadas: a relação entre a idade gestacional e o tamanho do vocabulário aos dois anos; a relação entre a idade gestacional e o uso de palavras descontextualizadas; a relação entre a idade gestacional e o desenvolvimento morfo-sintático; a associação entre a idade gestacional e os fatores familiares e a associação entre a idade gestacional e o desenvolvimento de linguagem, quando o baixo peso (PIG) foi levado em consideração.

Quanto aos resultados, pode-se detectar que as crianças nascidas extremamente prematuras apresentaram o tamanho do vocabulário semelhante ao das crianças nascidas a termo, mas as nascidas prematuras demonstraram um vocabulário inferior à media. No uso das palavras, houve uma melhor tendência para as palavras descontextualizadas pelas crianças nascidas a termo. No que se relaciona aos aspectos morfológicos e sintáticos, as crianças nascidas extremamente prematuras apresentaram maiores dificuldades, inclusive no tamanho das frases usadas.

No que se refere às características sociais, econômicas e educacionais, parece que os grupos de prematuros apresenta- 
ram maior número de nascimentos múltiplos, do que no grupo controle. Condições sócio-econômicas, educação materna, estabilidade familiar e número de membros na família não interferiram nas condições de linguagem apresentadas pelas crianças.

Aparentemente, apenas a idade gestacional não é suficiente para prejudicar o desenvolvimento de Linguagem.

A pesquisa revelou que os prematuros foram os mais prejudicados aos dois anos de idade.

Quanto mais precocemente eles nascem, maior o comprometimento no vocabulário e no uso de palavras descontextualizadas. Relativamente, os prematuros apresentam mais dificuldade para o uso de formas irregulares e combinação de palavras. Desta forma, pode-se concluir que a prematuridade pode ser associada ao aumento do risco para alterações de linguagem mais adiante.

O grupo do Reino Unido salientou a importância de se conhecer, se o desenvolvimento de prematuros extremos é realmente mais lento. As 288 crianças escolhidas (148 do sexo masculino e 140 do sexo feminino) nasceram de 28 semanas de gestação ou menos. Fatores demográficos, neonatais, sócioeconômicos, de crescimento e de alterações de linguagem foram investigados com análise multifatorial.

A avaliação também foi feita por meio do CDI-WS, além da utilização de questionário aos pais para o reconhecimento de outros elementos que pudessem também interferir.
A média de palavras apresentadas pelas crianças deste estudo aos dois anos foi de 42, enquanto que no outro, as crianças nascidas extremamente prematuras apresentavam o tamanho do vocabulário semelhante às nascidas a termo.

Após todas as análises multifatoriais realizadas com o nível de alteração, sexo, tempo de permanência no hospital e peso aos 12 meses, detectou-se que não houve associação significante entre a idade gestacional e o vocabulário e que não há significância quanto aos fatores sócio-econômicos. O outro estudo também afirmou que, aparentemente, apenas a idade gestacional não é suficiente para prejudicar o desenvolvimento de linguagem, mas que os fatores familiares podem reduzir tal interferência.

A conclusão do grupo do Reino Unido é de que os fatores clínicos dominam a correlação da aquisição de vocabulário, aos dois anos, de crianças nascidas extremamente prematuras.

Aparentemente, os dois estudos concluem que aos dois anos, as crianças nascidas extremamente prematuras ou apenas prematuras não apresentam graves evidências de prejuízos, mas não descartam a possibilidade de que possam existir riscos futuros, nesta população de crianças.

Tal conclusão nos induz a realizar avaliações de linguagem em idades mais tardias, como os pré-escolares e/ou escolares, na tentativa de verificar se o nascimento prematuro ou extremamente prematuro pode trazer consequiências funestas para o desenvolvimento da linguagem. 